\title{
Avaliação de diferentes protocolos utilizados na cicatrização umbilical em bezerros
}

Alexandra Melo Oliveira, Maria do Carmo Sales da Silva, Lucas da Costa Dutra, Débora Ferreira dos Santos Ângelo, Luana Teles Ramos, Karla Campos Malta", Isabela Araújo Rodrigues, Evaldo de Almeida Cardoso, Sara Vilar Dantas Simões

Clínica de Grandes Animais, Hospital Veterinário, Centro de Ciências Agrárias, Universidade Federal da Paraíba (UFPB), João Pessoa, PB, Brasil

*Autor correspondente

e-mail: karla@cca.ufpb.br

\section{Resumo}

A importância do tratamento do umbigo dos bezerros logo após o nascimento a fim de evitar a infecção umbilical e os graves problemas associados a elas já foi amplamente estudada, porém os problemas umbilicais são recorrentes nos rebanhos brasileiros. Protocolos de tratamento já foram também determinados, mas na prática observa-se grande resistência por parte dos tratadores e produtores na execução dos procedimentos. Em condições de campo observa-se preferência na utilização de sprays, devido a facilidade de sua execução e ao custo e dificuldades na aquisição do iodo, tratamento considerado o mais recomendado na literatura. Um outro aspecto que não tem boa aceitação é a recomendação de imergir o coto umbilical no iodo durante no mínimo um minuto; muitos tratadores apenas realizam a rápida imersão do coto. Em trabalhos de campo realizados por docentes e alunos da Universidade Federal da Paraíba (UFPB) na região do Brejo Paraibano, há relatos que o spray prata é eficiente no tratamento do umbigo. 0 objetivo desse trabalho foi avaliar a eficácia do uso do spray prata e da rápida imersão do umbigo no iodo em comparação ao tratamento de imersão no iodo a $7 \%$ por minuto, com o intuito de identificar procedimentos de cura do umbigo mais aceitos entre os produtores. Durante 10 meses foram acompanhados nascimentos de bezerros no Setor de Bovinocultura da UFPB. A medida que os bezerros nasciam os tratamentos eram intercalados, objetivando manter condições semelhantes para os tratamentos. Um total de vinte e três animais foi utilizado no experimento, sendo formados três grupos experimentais: G1 (iodo a 7\% por 1 minuto/9 animais), G2 (iodo a 7\% rápida imersão/7 animais) e G3 (spray prata/7 animais). 0 spray prata tinha na sua composição diclorvos - 1,7\%, cipermetrina - 0,5\%, alumínio metálico - 5,0\%, sulfadiazina de prata-0,1\%. Os tratamentos foram realizados duas vezes ao dia, durante três dias. Para avaliação da eficácia dos protocolos considerou-se o aspecto diário do cordão, sensibilidade à palpação, espessura das estruturas intra e extra-abdominais e quantidade de dias 
desde o nascimento até a queda do coto umbilical. As análises estatísticas demonstraram que não houve diferença significativa entre os tratamentos. Não foram observadas alterações sugestivas de processos inflamatórios ou infecciosos no cordão e a desidratação e o tempo de queda do coto umbilical foi semelhante em todos os tratamentos. Conclui-se que desde que se utilizem os protocolos conforme demonstrado nesse estudo, o prata e o iodo a 7\% em rápida imersão podem substituir o uso do iodo a 7\% por um minuto. 